\title{
Study on the Complex Analysis of Series Summation
}

\author{
Ling Chen \\ College of Mobile Telecommunications Chongqing University of Posts and Telecom \\ Chongqing University of Posts and Telecommunications College of mobile teaching reform of \\ higher education research project(YTJG201627, YTJG201626, YTJG201613) \\ Chongqing ,China 401520
}

\section{Keywords: Series summation; Complex analysis}

\begin{abstract}
In mathematical analysis, the problem of series summation plays an important role, and it is also the difficulty of mathematical analysis. In general, the solution to the series summation is obtained by the method of item by integration, definition, or item differentiation. In this paper, through the elementary analysis of mathematics, and using the method of complex analysis, some series summation of higher mathematics is analyzed.

If using the usual method of calculating on the series or the approximate value, whether it is an infinite series or a general series, the process will be particularly difficult and cumbersome. Therefore, there are a large number of scholars on the series summation, a large number of mathematical calculations and thinking from which to find out some special expression of the general term, and looking for the summary and analysis of some of the sum of the regularity of the solution. After deep mathematical results of previous studies, combined with complex residue theorem analysis, it calculated by summation of the series which are more effective.
\end{abstract}

\section{The Basis of Series Summation by Complex Analysis}

Complex analysis is a mathematical theory for the study of complex functions, and it is the result of the application and development of mathematical theory of real analysis in the field of complex numbers. For example, the limits of functions of one complex variable and one variable real function, because of the complex in the field of $\mathrm{z} \rightarrow \mathrm{Z} 0$ is pointing $\mathrm{z}$ from the complex plane angle to a fixed point $\mathrm{z} 0$ approach, if it exists, then the $\mathrm{Z}$ of each path from any direction closer to $\mathrm{z} 0$, which will eventually reach z0. The end result should be the same as a function of the limit, limit and a function of common values defined compared to existing, functions of one complex variable limit existence requirement that is more harsh and demanding, and it is also because of this complex function of calculus in mathematics, the mathematical theory of real analysis with a broader and deeper development and significance. [1]

First of all, assuming that the complex function is a function of a single result, and it can analyze the value of this function in addition to some isolated singular points except the D. So let $\mathrm{z} 0$ as isolated singular point in the area, represented by $\mathrm{C} 0$ in the circle, and the circle area inside has no other singularities of complex function, by Laurent theorem, Laurent can be expanded into a series of complex functions

$$
f(z)=\sum_{n=-\infty}^{\infty} a_{n}\left(z-z_{0}\right)^{n}
$$

It is assumed that the Laurent series converges uniformly within the circumference of the $\mathrm{C} 0$, and if the counterclockwise direction is the positive direction of the closed curve, then the integral of $\mathrm{C} 0$ in the Laurent series is:

$$
\oint_{\mathrm{C}_{0}} \mathrm{f}(\mathrm{z}) \mathrm{dz}=\oint_{\mathrm{C}_{0}} \sum_{\mathrm{n}=-\infty}^{\infty} \mathrm{a}_{\mathrm{n}}\left(\mathrm{z}-\mathrm{z}_{0}\right)^{\mathrm{n}} \mathrm{dz}=\sum_{\mathrm{n}=-\infty}^{\infty} \mathrm{a}_{\mathrm{n}} \oint_{\mathrm{C}_{0}}\left(\mathrm{z}-\mathrm{z}_{0}\right)^{\mathrm{n}} \mathrm{dz}
$$

According to the Cauchy integral formula, the existence of any integer $n$ :

$\oint_{C_{0}}\left(z-z_{0}\right)^{n} d z= \begin{cases}0, & n \neq-1 \\ 2 \pi i, & n=-1\end{cases}$

Because of the complex number, $\mathrm{i} 2=-1$, the (2) formula is replaced by the (3) formula

$\oint_{\mathrm{C}_{0}} \mathrm{f}(\mathrm{z}) \mathrm{dz}=2 \pi \mathrm{ia}{ }_{-1}$

For here function in $\mathrm{z} 0$ residues namely $\mathrm{a}-1$, labeled as Res (). 
Assuming that $\mathrm{C}$ is any contour in the range of the $\mathrm{D}$, and the singularity does not exist on the $\mathrm{C}$, it is assumed that in the region enclosed by the $\mathrm{C}$ line, there are $\mathrm{k}$ isolated singularities, respectively $\mathrm{z} 1, \mathrm{z} 2, \ldots, \mathrm{zk}$, and for each singular point, the point is the center of circle $\mathrm{C} 1, \mathrm{C} 2, \ldots, \mathrm{Ck}$, the $\mathrm{k}$ circles also does not intersect, and all circles are in the interior of the line $\mathrm{C}$, the Cauchy theorem can be seen

$$
\oint_{\mathrm{C}} \mathrm{f}(\mathrm{z}) \mathrm{dz}=\sum_{\mathrm{n}=1}^{\mathrm{k}} \oint_{\mathrm{C}_{\mathrm{n}}} \mathrm{f}(\mathrm{z}) \mathrm{dz}
$$

The article (4) and (5) are combined, it can get the following type of residue

$$
\oint_{\mathrm{C}} \mathrm{f}(\mathrm{z}) \mathrm{dz}=2 \pi \mathrm{i} \sum_{\mathrm{n}=1}^{\mathrm{k}} \operatorname{Res}\left(\mathrm{f} ; \mathrm{z}_{0}\right)=2 \pi \mathrm{i} \times \text { [C 内部所有留数的和] }
$$

The (6) is more practical when it is applied to many mathematical analysis of dynamical systems, linear algebra, functional analysis and analytic number theory. In particular, with the calculation of higher mathematics, some can not be answered by the general method of real function, and with this formula, it will have a special effect.

At the same time, the (6) also shows: if it can be left by numerical method of complex analysis, assuming the right function and contour, so that it can have some form of series, and then using the limit mode to handle, it can obtain the series and so through the method of complex analysis of series summation is possible.

\section{Calculation Methods of Residue in the Complex Analysis}

That function $\mathrm{z} 0$ is the isolated singular point, if it can believe that $\mathrm{z}=\mathrm{z} 0$ is a function of the removable singularity. $\lim _{\mathrm{z} \rightarrow \mathrm{z}_{0}}\left(\mathrm{z}-\mathrm{z}_{0}\right) \mathrm{f}(\mathrm{z})=0$ And if it can think, $\mathrm{z}=\mathrm{z} 0$ is a function of the pole, $\lim _{z \rightarrow z_{0}}|f(z)|=\infty$ and if $z 0$ is a function of the pole, and at the same time $f(z)\left(z-z_{0}\right)^{m}(m \in$ $\mathrm{N}^{*}$ ), then it can think that $\mathrm{z}=\mathrm{z} 0$ is a pole of order $\mathrm{m}$ function.

Computation of the singular point $\mathrm{z}=\mathrm{z} 0$ residue of commonly used mathematical methods that will function to the form (1), then $\operatorname{Res}()=\mathrm{a}-1$, but the $\mathrm{m}$ function has the following order pole residue calculation way:

$$
\operatorname{Res}\left(\mathrm{f} ; \mathrm{z}_{0}\right)=\frac{1}{(\mathrm{~m}-1) !} \lim _{\mathrm{z} \rightarrow \mathrm{z}_{0}} \frac{\mathrm{d}^{\mathrm{m}-1}}{\mathrm{dz}^{\mathrm{m}-1}}\left[\left(\mathrm{z}-\mathrm{z}_{0}\right)^{\mathrm{m}} \mathrm{f}(\mathrm{z})\right] \text {. }
$$

Note that if $\mathrm{z}=\mathrm{z} 0$ is the first pole of the function, then:

$\operatorname{Res}\left(\mathrm{f} ; \mathrm{z}_{0}\right)=\lim _{\mathrm{z} \rightarrow \mathrm{z}_{0}}\left(\mathrm{z}-\mathrm{z}_{0}\right) \mathrm{f}(\mathrm{z})$.

According to paragraph (7), if:

$$
\mathrm{f}(\mathrm{z})=\frac{\mathrm{g}(\mathrm{z})}{\mathrm{z}-\mathrm{z}_{0}}
$$

On behalf of analytic functions, and $\neq 0$, then $\operatorname{Res}()=$,

$\mathrm{f}(\mathrm{z})=\frac{\mathrm{g}(\mathrm{z})}{\left(\mathrm{z}-\mathrm{z}_{0}\right)^{\mathrm{m}}}$

In the formula, it also represents the analytic function, and $\neq 0, \mathrm{~m}$ is an integer, and $\operatorname{Res}\left(\mathrm{f} ; \mathrm{z}_{0}\right)=\frac{1}{(\mathrm{~m}-1) !} \mathrm{g}^{\mathrm{m}-1}\left(\mathrm{z}_{0}\right)$

Note that if it is a pole of order function, and it is analytic functions with an open set, then:

$\operatorname{Res}\left(f ; z_{0}\right)=g\left(z_{0}\right) \operatorname{Res}\left(f ; z_{0}\right)(12)$

\section{Part Three, the Application of Complex Analysis of Series Summation}

Assume that the function is limited in the complex plane, isolated singularity [1] can make analysis, $0 \leq|\mathrm{z} 1|<|\mathrm{z} 2|<\ldots<|\mathrm{zn}|<\ldots$ If taking a closed curve $\mathrm{Cn}$, it can let $\left\{\mathrm{z}_{\mathrm{k}=1}^{\mathrm{n}}\right\}$ in the closed curve $\mathrm{Cn}$ surrounded by the scope of the (6):

$$
2 \pi \mathrm{i} \sum_{\mathrm{k}=1}^{\mathrm{n}} \operatorname{Res}\left(\mathrm{f} ; \mathrm{z}_{0}\right)=\oint_{\mathrm{C}_{\mathrm{n}}} \mathrm{f}(\mathrm{z}) \mathrm{dz}
$$

If selecting the appropriate closed curve $\mathrm{Cn}$ and function

$$
\lim _{n \rightarrow+\infty} \oint_{C_{n}} f(z) d z=0
$$


Then it can get the formula of the series.

Theorem 1 assumes that $\left\{\mathrm{zk}_{\mathrm{k}=1}^{\mathrm{m}}\right\}$ is an isolated singularity of a function, and that these points are not integer points on the real axis, if there are $\varepsilon>0, K>0, R 0>0$, and function:

$$
|\mathrm{f}(\mathrm{z})| \leq \frac{\mathrm{K}}{|\mathrm{z}|^{1+\varepsilon}} \quad,|\mathrm{z}|>\mathrm{R} 0
$$

So

$\sum_{\mathrm{n}=-\infty}^{\infty} \mathrm{f}(\mathrm{n})=-\pi \sum_{\mathrm{k}=1}^{\mathrm{m}} \operatorname{Res}\left(\mathrm{f}(\mathrm{z}) \cot \pi \mathrm{z} ; \mathrm{z}_{\mathrm{k}}\right)$

Evidence can be obtained, in $\mathrm{z}=0, \pm 1, \pm 2, \ldots$ When is the pole, assuming that $\mathrm{n} \in \mathrm{Z}$, then through the L'Hospital rule:

$$
\lim _{\mathrm{z} \rightarrow \mathrm{n}}(\mathrm{z}-\mathrm{n})^{2} \cot \pi \mathrm{z}=\lim _{\mathrm{z} \rightarrow \mathrm{n}} \frac{(\mathrm{z}-\mathrm{n})^{2} \cos \pi \mathrm{z}}{\sin \pi \mathrm{z}}=\lim _{\mathrm{z} \rightarrow \mathrm{n}} \frac{2(\mathrm{z}-\mathrm{n}) \cos \pi \mathrm{z}-(\mathrm{z}-\mathrm{n})^{2} \pi \sin \pi \mathrm{z}}{\pi \cos \pi \mathrm{z}}=0
$$

So when $\mathrm{z}=\mathrm{n}$ and $\mathrm{n} \in N, \mathrm{z}$ is the first order pole, through the first (8) and combined with the law of:

$$
\operatorname{Res}(\cot \pi z ; n)=\lim _{z \rightarrow n}(z-n) \cot \pi z=\lim _{z \rightarrow n} \frac{(z-n) \cos \pi z}{\sin \pi z}=\lim _{z \rightarrow n} \frac{\cos \pi z-(z-n) \pi \sin \pi z}{\pi \cos \pi z}=\frac{1}{\pi}
$$

When $\mathrm{N} \in \mathrm{N}^{*}, \mathrm{CN}$ is in the complex plane, and the center is the origin of the vertex respectively:

$$
(1+\mathrm{i})\left(\mathrm{N}+\frac{1}{2}\right),\left(\mathrm{N}+\frac{1}{2}\right)(-1+\mathrm{i}),\left(\mathrm{N}+\frac{1}{2}\right)(-1-\mathrm{i}),(1-\mathrm{i})\left(\mathrm{N}+\frac{1}{2}\right)
$$

If the function of the singular point set $\left\{\mathrm{zk}_{\mathrm{k}=1}^{\mathrm{m}}\right\}$ exists in the square closed curve of $\mathrm{CN}$, then according to the (6), the (12), the (18) formula, it can be obtained:

$$
\oint_{\mathrm{C}_{\mathrm{N}}} \mathrm{f}(\mathrm{z}) \cot \pi \mathrm{zdz}=2 \pi \mathrm{i}\left\{\sum_{\mathrm{n}=-\mathrm{N}}^{\mathrm{N}} \operatorname{Res}(\mathrm{f}(\mathrm{z}) \cot \pi \mathrm{z} ; \mathrm{n})+\sum_{\mathrm{n}=-\mathrm{N}}^{\mathrm{N}} \operatorname{Res}\left(\mathrm{f}(\mathrm{z}) \cot \pi \mathrm{z} ; \mathrm{z}_{\mathrm{k}}\right)\right\}=
$$
$2 \pi \mathrm{i}\left\{\sum_{\mathrm{n}=-\mathrm{N}}^{\mathrm{N}} \operatorname{Res}(\mathrm{f}(\mathrm{z}) \cot \pi \mathrm{z} ; \mathrm{n})+\sum_{\mathrm{n}=-\mathrm{N}}^{\mathrm{N}} \operatorname{Res}\left(\mathrm{f}(\mathrm{z}) \cot \pi \mathrm{z} ; \mathrm{z}_{\mathrm{k}}\right)\right\}=$

$$
2 \mathrm{i} \sum_{\mathrm{n}=-\mathrm{N}}^{\mathrm{N}} \mathrm{f}(\mathrm{n})+2 \pi \mathrm{i} \sum_{\mathrm{k}=1}^{\mathrm{m}} \operatorname{Res}\left(\mathrm{f}(\mathrm{z}) \cot \pi \mathrm{z} ; \mathrm{z}_{\mathrm{k}}\right)
$$

If it can prove:

$$
\lim _{N \rightarrow \infty} \oint_{C_{N}} f(z) \cot \pi z d z=0
$$

Then section (16) is established

In order to prove (19) is correct, first of all it needs to confirm

$$
\left|\oint_{C_{N}} f(x) \cot \pi z d z\right|
$$

Because each side of the square is $2 \mathrm{~N}+1$, the total length of the closed curve is $8 \mathrm{~N}+4$, and the $\operatorname{sinht}=\frac{\mathrm{e}^{\mathrm{t}}-\mathrm{e}^{-\mathrm{t}}}{2}, \cos \mathrm{ht}=\frac{\mathrm{e}^{\mathrm{t}}+\mathrm{e}^{-\mathrm{t}}}{2}$

$t$ is a real number in the formula, which can be obtained by Euler formula:

sin it $=\frac{\mathrm{e}^{\mathrm{i}(\mathrm{it})}-\mathrm{e}^{-\mathrm{i}(\mathrm{it})}}{2 \mathrm{i}}=-\frac{\mathrm{e}^{\mathrm{t}}-\mathrm{e}^{-\mathrm{t}}}{2 \mathrm{i}}=\mathrm{i} \frac{\mathrm{e}^{\mathrm{t}}-\mathrm{e}^{-\mathrm{t}}}{2}=\mathrm{i} \operatorname{sinht}$

meanwhile

$\cos$ it $=\cos h t$

If $\mathrm{z}=\mathrm{x}+\mathrm{iy}$, the sine formula and the two horns and (23), (24) can get: $\sin z=\sin (x+i y)=\sin x \cosh y+i \sin h y \cos x$

And

$$
\begin{gathered}
\sin ^{2} h t=\left(\frac{\mathrm{e}^{\mathrm{t}}-\mathrm{e}^{-\mathrm{t}}}{2}\right)^{2}=\frac{\mathrm{e}^{2 \mathrm{t}}+\mathrm{e}^{-2 \mathrm{t}}}{4}-\frac{1}{2} \\
\cos ^{2} \mathrm{ht}=\left(\frac{\mathrm{e}^{\mathrm{t}}+\mathrm{e}^{-\mathrm{t}}}{2}\right)^{2}=\frac{\mathrm{e}^{2 \mathrm{t}}+\mathrm{e}^{-2 \mathrm{t}}}{4}+\frac{1}{2}
\end{gathered}
$$

General (26) and (27), it is available: $\cos ^{2} \mathrm{ht}=1+\sin ^{2} \mathrm{ht} \quad(28)$

General (25) and (28), it is available:

$$
|\sin z|^{2}=\sin ^{2} x+\sin ^{2} \text { hy }
$$

Also have:

$=\cos ^{2} \mathrm{x}+\sin ^{2} \mathrm{hy}$

General (29) and (30), it is available: 
$|\cot \pi z|^{2}=\frac{\cos ^{2} \pi x+\sin ^{2} h \pi y}{\sin ^{2} \pi x+\sin ^{2} h \pi y} \leq \frac{\cos ^{2} \pi x}{\sin ^{2} \pi x+\sin ^{2} h \pi y}+1$

On the vertical line of the closed curve $\mathrm{CN}$, so

$\cos \pi x=0, \sin \pi x= \pm 1, z=x+i y \in C_{N}$ 的垂线

General (31) and (32), it is available:

$|\cot \pi \mathrm{z}|^{2} \leq 1, \mathrm{z} \in \mathrm{C}_{\mathrm{N}}$ 的垂线 (33)

Closed curve $\mathrm{CN}$ horizontal line, $|\mathrm{y}|=\mathrm{N}+\frac{1}{2}$, it is available:

$|\operatorname{sinhy\pi }| \geq \frac{\mathrm{e}^{\pi\left(\mathrm{N}+\frac{1}{2}\right)-1}}{2}$

So there if level of

$\lim _{\mathrm{N} \rightarrow \infty}|\operatorname{sinhy\pi }|=+\infty, \mathrm{z}=\mathrm{x}+\mathrm{iy} \in \mathrm{C}_{\mathrm{N}}$ 的水平线 (35)

Composite (31), (32) and (35), there will be a constant $\mathrm{M}$, for any $\mathrm{N}$ meet:

$|\cot \pi \mathrm{z}| \leq \mathrm{M}, \mathrm{z} \in \mathrm{C}_{\mathrm{N}}$

General (15) and (36), when the $\mathrm{N}$ is sufficiently large, the:

$\lim _{N \rightarrow \infty}\left|\oint_{C_{N}} f(z) \cot \pi z d z\right| \leq \lim _{N \rightarrow \infty} K M \frac{8 N+4}{N^{1+\epsilon}}=0$

So

This can be (20) established with theorem proving.

\section{Reference}

[1]Ning Xu,Complex analysis method of series summation[J].Journal of Nanjing Normal University (Natural Science Edition) 